
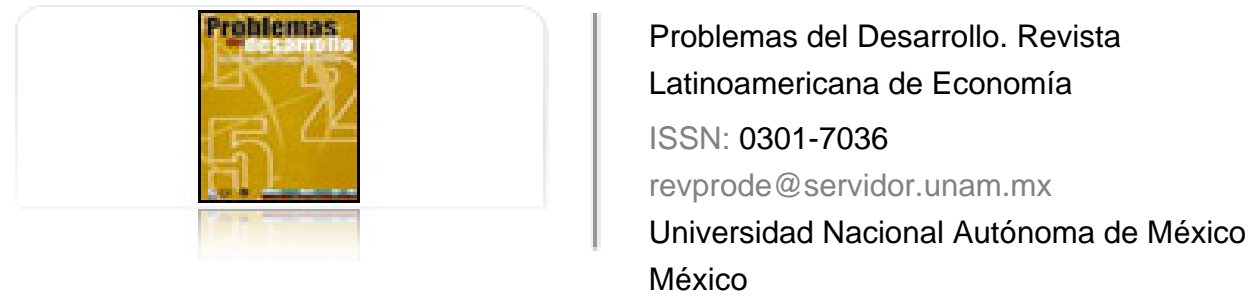

Lechini, Gladys; Giaccaglia, Clarisa

El ascenso de Brasil en tiempos de Lula ¿Líder regional o jugador global?

Problemas del Desarrollo. Revista Latinoamericana de Economía, vol. 41, núm. 163, octubre-

diciembre, 2010, pp. 53-73

Universidad Nacional Autónoma de México

Distrito Federal, México

Disponible en: http://www.redalyc.org/articulo.oa?id=11819762004

- Cómo citar el artículo

- Número completo

- Más información del artículo

Página de la revista en redalyc.org

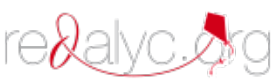

Sistema de Información Científica

Red de Revistas Científicas de América Latina, el Caribe, España y Portugal Proyecto académico sin fines de lucro, desarrollado bajo la iniciativa de acceso abierto 
Revista Problemas del Desarrollo, 163 (41), octubre-diciembre 2010

\title{
El asCenso de Brasil EN TIEMpos de LULA ¿LÍDER REGIONAL O JUGADOR GLOBAL?
}

\author{
Gladys Lechini* y Clarisa Giaccaglia**
}

Fecha de recepción: 28 de junio de 2010. Fecha de aceptación: 19 de agosto de 2010.

"Nunca tuve un trauma por haber cambiado de postura
porque veo la politica con un gran pragmatismo.
En politica se hace lo que se puede hacer. En el discurso
uno puede decir lo que quiere, pero en el momento
de ejecutar, el limite es lo posible".
Lula da Silva, abril de 2009

RESUMEN

Al observar el creciente involucramiento de Brasil en los escenarios regionales y globales durante la gestión externa del presidente Lula da Silva, el presente trabajo apunta a responder las siguientes preguntas: ¿cuál es el rol que pretende ejercer actualmente el Estado brasileño en el sistema internacional? ¿Cuál es el límite de los compromisos internacionales de Brasil? ¿Existe un doble estándar entre su comportamiento global y regional? Como si se tratara de un juego en un laberinto de espejos que distorsionan los reflejos, pareciera que Brasil intenta "agrandar" o "minimizar" sus cualidades según las circunstancias así lo exijan.

\section{PALABRAS CLAVE}

Brasil, política exterior, liderazgo regional, potencia media, autonomía.

Profesora titular de Relaciones Internacionales en la Universidad Nacional de Rosario (UNR). Investigadora del CONICET. Directora Programa de Cooperación y Relaciones Sur-Sur (PRECSUR)

** Licenciada en Relaciones Internacionales de la Universidad Nacional de Rosario (UNR). Becaria Doctoral del conICET 
Gladys Lechini y Clarisa Giaccaglia

\section{Summary}

Looking at the growing involvement of Brazil in regional and global scenarios under the foreign policy management of President Lula da Silva, this study seeks to answer the following questions: What is the role the Brazilian State seeks to play in the international system? What is the limit of Brazil's international commitments? Does a double standard exist in its global and regional performance? As if we were playing a game in a labyrinth of distorting mirrors, it would seem that Brazil is trying to "blow up" or "minimize" its qualities according to what the circumstances demand.

Key words: Brazil, foreign policy, regional leadership, middle power, autonomy.

\section{Résumé}

Au vu de l'implication croissante du Brésil sur les scènes régionale et globale durant la gestion extérieure du président Lula da Silva, le présent travail vise à répondre aux questions suivantes : quel est le rôle que prétend jouer actuellement l'État brésilien dans le système international ? quelle est la limite des engagements internationaux du Brésil ? Existe-t-il deux standards distincts pour ses comportements global et régional ? Comme s'il s'agissait d'un jeu dans un labyrinthe de miroirs déformants, il semblerait que le Brésil essaie d' " amplifier » ou de « minimiser » ses qualités selon ce que les circonstances exigent.

Mots clés : Brésil, politique extérieure, leadership régional, moyenne puissance, autonomie.

\section{Resumo}

Observando o crescente envolvimento do Brasil nos cenários regional e global durante a gestấo externa do presidente Lula da Silva, este trabalho visa responder às seguintes perguntas: qual é o papel que pretende exercer o Estado brasileiro no sistema internacional? Qual é o limite dos compromissos internacionais do Brasil? Existe um padrão duplo entre o seu comportamento global e regional? Como se fosse um jogo em um labirinto de espelhos que distorcem os reflexos, parece que o Brasil tenta "ampliar" ou "minimizar" as suas qualidades conforme é exigido pelas circunstâncias.

Palavras-chave: Brasil, política externa, liderança regional, potência média, autonomia.

卢拉时代巴西的崛起，区域性的领导还是全球参与者？

综述

通过观察鲁拉时代的巴西在地区和国际事务越来越活跃的表现），本文旨 在回答以下问题：巴西目前在国际体系中的作用是什么?巴西的国际承诺 的极限是什么? 其全球性和区域性的行为是否有双重标准?。好像它是玩 在一个扭曲的镜子反射迷宫游戏, 似乎巴西, 根据需要, 试图 “放大” 或 “减小”他的品质。

关键词：巴西，一外交政策－地区领导－中等性大国－自主权。 
El ascenso de Brasil en tiempos de Lula zlíder regional o jugador global?

\section{INTRODUCCIÓN}

En la literatura especializada se observa que la mayoría de los académicos, políticos y diplomáticos reconoce a Brasil como una de las naciones del conjunto de potencias medias, tanto por sus recursos territoriales, demográficos y económicos, como por la formulación y ejecución de una política exterior comúnmente citada "como el ejemplo tal vez más acabado de una conducta internacional definida y consecuente" (Perez Llana, 1981: 369).

En tanto, el liderazgo ejercido por Brasil, por ejemplo, en el G-20 -en el marco de las negociaciones comerciales de la Organización Mundial del Comercio (OMC)-, o su rol en el G-4 -con el objeto de lograr un asiento permanente en el Consejo de Seguridad de Naciones Unidas-, demuestran el progresivo interés del gobierno brasileńo por aumentar su participación en los asuntos mundiales. No obstante, cierta resistencia interna así como el recelo manifestado por los países vecinos frente a estas aspiraciones, provocan que el gobierno busque relativizar su poder en su área de influencia.

Para países como Brasil, las instituciones internacionales representan la oportunidad de contar con un espacio político donde puedan "liderar" el proceso de formación de algunas normas internacionales, desestimando aquellas reglas o prácticas que puedan afectarlos y promoviendo aquéllas que puedan favorecerlos (Hurrell, 2000: 4).

En el proceso de ejercicio de liderazgo, tanto Brasil como otras potencias medias del Sur, aparecen representando a su región y defendiendo sus intereses. Esta actitud se mantendrá en la medida en que persista la convergencia entre los intereses del grupo y los propios. Pero si las aspiraciones se distancian, estos líderes regionales antepondrán sus intereses nacionales o sectoriales frente a los regionales.

Por otra parte, muchas veces se enfrentan a tomar decisiones que los colocan del lado del hegemón mundial ("cola de león" o bandwagoning) en su camino para consensuar normas en torno a determinados objetivos que los beneficien y cuando abandonan la representación del grupo. Caso contrario, refuerzan el liderazgo en busca de mayores márgenes de autonomía junto a Estados similares o más pequeños ("cabeza de ratón").

Frente al mencionado creciente involucramiento de Brasil en los escenarios regionales y globales, cabe preguntarse ¡cuál es el rol que ejerce o pretende ejercer actualmente el Estado brasileño en el sistema internacional? ¿Cuál es el límite de los compromisos internacionales de Brasil? ¿Hasta qué punto sus intereses son globales? ¿Está dispuesto a jugar el juego de los líderes regionales? ¿Existe coincidencia entre las élites políticas y económicas sobre un posible "destino manifiesto" de este país sudamericano de porte regional?

Como si se tratara de un juego en un laberinto de espejos que distorsionan los reflejos, pareciera que Brasil intenta "agrandar" o "minimizar" sus cualidades según lo exijan las circunstancias.

Para abordar estas cuestiones reflexionaremos sobre el rol de líder regional de Brasil a través del análisis de los discursos y las acciones ${ }^{1}$ implementadas durante la gestión

A los fines de este trabajo y por una cuestión de extensión del mismo, haremos mención solamente a algunos ejemplos considerados significativos para mostrar nuestra posición 
Gladys Lechini y Clarisa Giaccaglia

externa del presidente Lula da Silva con el objeto de mostrar el doble estándar de su comportamiento global y regional.

\section{LAS ESTRATEGIAS DE BRASIL PARA OPTIMIZAR SU INSERCIÓN INTERNACIONAL}

Desde la finalización de la Guerra Fría, Brasil busca consolidar su proyección mundial al incrementar su participación en los foros políticos y económicos regionales y multilaterales y así disminuir la vulnerabilidad del país y aumentar el propio poder. Es lo que Letícia Pinheiro caracteriza como "institucionalismo pragmático" (Pinheiro: 2004).

Además de asegurarse un lugar destacado en las discusiones de los principales temas de la agenda internacional, Brasil busca fortalecer el multipolarismo y el rol de las organizaciones internacionales como instancias de ordenamiento mundial, junto a la profundización de las relaciones con los nuevos polos de poder.

En sintonía con esta línea, Vigevani y Ramanzini Jr. señalan la existencia de dos conceptos que ayudan a entender el actual comportamiento de Brasil que funcionan como fundamento de su política exterior: universalismo y autonomía.

"Estos conceptos, social e históricamente construidos, se insertan en el conjunto de percepciones subjetivas que informan las acciones de los actores políticos, forman parte de los marcos cognitivos que influyen en la diplomacia brasileńa y corroboran su retórica de tradición y continuidad" (Vigevani-Ramanzini Jr., 2009: 82).

El universalismo como matriz conceptual de la política exterior brasileńa acompańa la transformación de Brasil de un global trader (un país que tiene un intercambio comercial con muchos países) a un global player (un Estado que aspira a lograr una inserción global con políticas exteriores globales).

En tanto la idea de autonomía apunta al incremento de los márgenes de maniobra en los escenarios regionales y globales. Tanto la autonomía solitaria como la solidaria ${ }^{2}$ permitirían la creación de una plataforma más amplia que contribuiría a sumar poder a las negociaciones internacionales encaradas por Brasil. En el nuevo marco internacional, actuar de manera conjunta permitiría aumentar el peso relativo de cada país individual.

Es por ello que desde la "autonomía por la distancia", característica del periodo bipolar (Fonseca, 1998), Brasil transitó posteriormente a la "autonomía por la participación", para avanzar, durante el gobierno de Lula, a la "autonomía por la diversificación" que

La autonomía solitaria es aquella que busca obtener mayores márgenes de maniobra internacional priorizando los intereses nacionales, mientras que la autonomía solidaria enfatiza la existencia de marcos regionales como medio para incrementar los márgenes de acción de un área en su conjunto (Giaccaglia, 2009:1). 
se refleja en su intensa actuación en diversas organizaciones internacionales (VigevaniRamanzini Jr., 2009).

Es en este contexto que el canciller Celso Amorim, al efectuar un balance de la actuación internacional del primer gobierno de Luiz Inácio Lula da Silva, afirmó que "Brasil cambió la dinámica de las negociaciones de la OMC. No fue solamente Brasil. Pero Brasil lidera el G-20 y es buscado -y diría que casi cortejado- por EEUU, la UE y Japón, entre otros países". ${ }^{3}$

Sin embargo, y a pesar de estas declaraciones de Celso Amorin, creemos importante marcar la ambivalencia y dicotomía que anima al ejecutivo brasileño en función de los escenarios y de la audiencia; pareciera que en los contextos globales Brasil tiende a mostrarse como líder de la región, en tanto en los espacios regionales asume una posición que enfatiza la colaboración entre pares.

Si Brasil pretende jugar un rol regional o autoerigirse como líder de la región defendiendo sus intereses en foros globales, su gobierno deberá mostrar condiciones para ofrecer concesiones a reivindicaciones regionales puntuales. Caso contrario terminarán prevaleciendo las soluciones no cooperativas al no existir la capacidad política de producir un efecto spill over, fortaleciendo los intereses comunes por sobre los individuales.

\section{a) En el ámbito global: un jugador en las grandes ligas multilaterales}

A lo largo de su historia, las élites brasileñas concibieron y auto-identificaron a su país como potencia media en condiciones de ejercer un rol relevante en el escenario internacional.

Estas aspiraciones se mostraron tempranamente en ocasión de la formación de la Sociedad de Naciones en 1919. Brasil fue la única nación sudamericana que participó en la Primera Guerra Mundial como beligerante. El país se sentía más cercano a las grandes potencias que a los Estados menores y, en consecuencia, realizó un pedido secreto para ser incorporado como miembro permanente del Consejo. El gobierno brasileño, señalando la ausencia de Estados Unidos en la Sociedad, se propuso a sí mismo como líder de los países latinoamericanos, teniendo en cuenta que Brasil era la siguiente mayor potencia americana (Holbraad, 1989: 68). Sin embargo, se retiró del organismo cuando las grandes potencias hicieron caso omiso de sus pretensiones e incorporaron a Alemania a la Liga de Naciones como miembro permanente del Consejo.

De esta manera, por primera vez quedó demostrado el auto-reconocimiento explícito de Brasil como potencia media. En este caso, no sólo se consideró digno de poseer un sitio permanente por sus capacidades materiales sino también por sus condiciones para representar a todo el continente latinoamericano.

3 “Brasil não Perdeu Prestígio. Ele Nunca Foi Tăo Alto", en Gazeta Mercantil, 19/10/2006. 


\section{Gladys Lechini y Clarisa Giaccaglia}

Años más tarde, en el marco de los debates para la creación de Naciones Unidas, nuevamente expuso sus intenciones de participar en el Consejo de Seguridad. Varias potencias medias como Canadá y Australia sostuvieron durante las negociaciones que el Consejo debía estar compuesto por aquellos Estados que habían contribuido militarmente en el pasado o que estaban dispuestos a asumir responsabilidades importantes de seguridad en el futuro. Este criterio, no obstante, no podía ser apoyado por Brasil cuya contribución durante la guerra había sido menor. Aunque el país latinoamericano destacó los recursos económicos y la ubicación geográfica como criterio de selección para la determinación de los miembros del Consejo de Seguridad. Otra vez las aspiraciones brasileñas debieron dejarse de lado.

Durante la Guerra Fría, Brasil adoptó un bajo perfil en los asuntos de paz y seguridad internacionales, pero llevó adelante un rol destacado en las negociaciones económicas coordinando coaliciones de países del Tercer Mundo, especialmente en el seno del Grupo de los 77 (Soares De Lima-Hirst, 2006: 6).

Ya en la pos Guerra Fría y como consecuencia de su crecimiento económico -el paso, en menos de 50 años, de país agrario a país industrial- las aspiraciones de Brasil a obtener mayores cuotas de poder decisional en el escenario mundial se vieron con mayores posibilidades. Esta nueva situación permitió a Brasil mostrarse como un actor relevante en términos de soft power ${ }^{4}$ a través de su determinación de participar en la formación de reglas y regímenes internacionales.

En los inicios del siglo XXI, las élites gobernantes parecen decididas a llevar adelante una estrategia continental y ganar protagonismo en el plano mundial. Consecuentemente, el gobierno brasileño se "mira" en los espejos que "agrandan" su imagen, promoviendo la presencia del país en los escenarios en los que se mueven las grandes potencias, tales como el G-8 o el Foro Económico Mundial. ${ }^{5}$ Asimismo, una serie de acciones como la condena a la agresión a Irak en el 2003, el apoyo a la reivindicación palestina o el intento de mediación con el gobierno de Teherán por su programa nuclear, ${ }^{6}$ demuestran el interés brasileño por mantener una política exterior independiente que le permita aumentar sus márgenes de maniobra internacional.

4 El soft power o poder cooptivo fue definido por Joseph Nye como la capacidad de una nación de estructurar una situación de forma tal que otras naciones desarrollen preferencias o definan sus intereses de forma coherente con aquella nación. Este tipo de poder tiende a surgir de recursos tales como la atracción cultural, la ideología o las reglas e instituciones de los regímenes internacionales (Nye, 1991: 84).

5 La relevancia de los escenarios se demuestra con la presencia del propio Lula en el Foro Económico Mundial de Davos en 2003, 2005 y 2007. En cuanto a los encuentros del G-8, el presidente brasileńo participó del "Diálogo ampliado" en Evian en 2003, en San Petesburgo en el 2006 y en Berlín en el 2007.

6 En mayo de 2010, el presidente Lula visitó Irán con el propósito de reabrir un canal de diálogo entre el gobierno de dicho país y la comunidad internacional en el marco de las negociaciones para la realización de un acuerdo nuclear. En ese contexto, Brasil considera que el gobierno iraní tiene derecho a desarrollar un programa nuclear siempre que su única finalidad sea obtener energía y no se desvíe la tecnología a objetivos militares. Sin embargo, con Estados Unidos como cabeza visible, diversas potencias occidentales defienden la idea de que Naciones Unidas sancione a Teherán argumentando que el gobierno de Ahmadineyad pretende disponer de armas nucleares (BBC mundo, 13/05/2010). 
En los ámbitos globales, el gobierno brasileño deja de lado todo discurso de confrontación con las grandes potencias, reconociendo la importancia de conservar buenas relaciones. La periodicidad con la cual Lula da Silva se ha reunido con los mandatarios de los grandes poderes del mundo es remarcable. Ha visitado Estados Unidos todos los años, participando en un importante número de encuentros. ${ }^{7}$ Entre ellos, en marzo de 2007 destacó su visita a Camp David para encontrarse con su par George W. Bush. En dicha ocasión, ambos firmaron un tratado de colaboración tecnológica para la producción de biocombustibles. ${ }^{8}$ Este acuerdo se produjo pese a que el gobierno brasileño había acusado en varias oportunidades a la administración norteamericana de mantener un doble discurso sobre este combustible y el cambio climático y de imponer trabas a su importación. Sin embargo, en el marco de este entendimiento, el presidente brasileño afirmó: "Los acuerdos que firmamos y los que vamos a firmar en el futuro, pueden garantizar que las relaciones entre Brasil y Estados Unidos no sólo sean necesarias sino estratégicas para un nuevo modelo de desarrollo y una nueva política social". ${ }^{\text {? }}$

En este contexto es importante señalar que si bien la superpotencia norteamericana podría no aceptar una hegemonía brasileña en América Latina, el gobierno estadounidense lleva adelante una estrategia de respaldo y cooperación con la potencia regional, a la cual Nolte (2006: 20) caracteriza como "lugarteniente de los Estados Unidos". Los orígenes de dicha estrategia pueden encontrarse en la Doctrina Nixon de los años setenta, la que incluyó a Brasil como uno de los "países llave", como un aliado preferencial de Estados Unidos llamado a asumir mayores responsabilidades en su región debido a que: "As Brazil goes, so will go the rest of that Latin American continent" ${ }^{10}$ Esta concepción se mantuvo cuando Condoleezza Rice, en ocasión de su visita a Brasil en abril de 2005, catalogó a Brasil como: "a regional leader" y "a growing global presence". ${ }^{11}$ Un posible acercamiento entre ambos países requiere cierta coincidencia de ideas entre Estados Unidos y Brasil. Asimismo conjura el riesgo de que si la superpotencia permite un mayor margen de acción a la potencia media, ésta termine confrontando al poder mundial al perseguir sus propios intereses.

7 En el ámbito privado, asistió a reuniones tales como la del Consejo de Relaciones Internacionales en 2003 y Global Compact Leaders Summit -que reúne a empresas comprometidas con el principio de responsabilidad corporativa- en 2004

8 El etanol, elaborado a partir de azúcar y almidón, es un combustible ecológico para automóviles con el cual se busca reducir el consumo de derivados del petróleo. Brasil es uno de los pioneros en el uso del etanol, con más de la mitad de los vehículos nuevos producidos en el país equipados con motores que pueden funcionar con etanol o gasolina o con ambos. Actualmente, Brasil es el segundo productor mundial de etanol tras Estados Unidos, y entre ambos producen el $70 \%$ del total mundial.

9 "Estados Unidos y Brasil firman acuerdos sobre biocombustibles", televisora Vive, 2 de abril de 2007. En sitio web: http://www.vive.gob.ve/inf_art.php?id_not=3914\&id_s=6\&id_ss=2\&pag=1

10 Expresión utilizada por el entonces presidente de Estados Unidos Richard Nixon en diciembre de 1971.

11 "Lula Watch: focusing on the Latin American Left", 26 de mayo de 2005. En sitio web: http://www.tfp.org/lulawatch/ v3_may31/1.html 
Gladys Lechini y Clarisa Giaccaglia

En este sentido, Drezner (2007) sostiene que en el actual sistema internacional, Estados Unidos debe "mantener cerca a los viejos amigos del país, y a sus nuevos amigos, aún más cerca”. El autor explica esta recomendación asegurando que si las potencias emergentes (entre las cuales considera a Brasil) no se integran a las estructuras internacionales existentes, podrían crear nuevas organizaciones internacionales que choquen con los intereses estadounidenses.

En el discurso brasileño queda claro cómo el gobierno se posiciona como líder frente al hegemón, mostrando sus potencialidades. En un seminario organizado por los periódicos Valor Económico y The Wall Street Journal en Nueva York, el Canciller Amorim se refirió a "dois temas importantes para o Brasil": Haití y el Fórum IBSA (India, Brasil y Sudáfrica).

En relación a la primera cuestión, sostuvo que: "o Brasil está presente no Haiti e procura ajudar no processo de recuperação desse país. Pela primeira vez, o Brasil lidera uma ação de paz que também é voltada para o desenvolvimento" (Amorim, 16/03/2009). La elección del tema de Haití por parte del canciller Amorim al momento de tomar la palabra en territorio estadounidense, no puede considerarse azaroso y debería, por tanto, explicarse por la intención brasileńa de demostrar a la superpotencia su capacidad de ejercer liderazgo en la región, también en cuestiones militares.

En cuanto al segundo tema, el Forum IBSA, Celso Amorim señaló: "o Brasil tomou a iniciativa de propor a criação de novos fóruns, como, por exemplo, o Fórum ÍndiaBrasil-África do Sul. Pela primeira vez, os três países, três grandes democracias, e multiculturais, criam um fórum para discutir diversas questôes com importância pra a paz". En este sentido cabe destacar que el grado de iniciativa para la conformación de bloques o alianzas también es considerado un indicador de liderazgo (Amorim, 16/03/2009).

En cuanto a Europa, se observa la asistencia de Lula a diversos encuentros empresariales que abordaron las posibilidades económicas de Brasil, ${ }^{12}$ así como la presencia de líderes europeos en la capital brasileña. A modo de ejemplo, es posible citar sus palabras durante la visita de la canciller alemana Angela Merkel, cuando señaló: "O Brasil, no Mercosul e no G-20, e a Alemanha, na União Européia, têm condiçóes de exercer uma liderança inovadora e construtiva" (Lula Da Silva, 14/05/2008). De esta manera, el presidente brasileño confirma doblemente el liderazgo de su país al colocarlo como "cabeza” del Mercosur y del G-20 y como "par" de Alemania en la tarea de ejercer un liderazgo innovador y constructivo.

Con respecto al Asia, Lula visitó los principales centros de poder. Fue a la India en varias oportunidades (más aún debido a su participación conjunta en IBSA), estuvo en China en 2004 y en Seúl y Japón en 2005, año en el que también se reunió con el mandatario ruso. Posteriormente, en mayo de 2010, inició una gira que incluyó Irán, Qatar y Rusia.

12 En Madrid (2003), Ginebra (2004), París (2005), Londres (2006), Helsinki, Estocolmo y Copenhague (2007), La Haya (2008) y Estambul (2009). 
La auto-percepción de Brasil como potencia media ha sido el resultado de una diplomacia activa que lo ha llevado a un mayor involucramiento en las instituciones internacionales. Como parte de este protagonismo, desde Brasilia se ha manifestado nuevamente el interés por participar como miembro permanente del Consejo de Seguridad de Naciones Unidas promoviendo un sistema de alianzas que pueda contribuir a respaldar sus aspiraciones junto a Japón, Alemania e India, con quienes ya forma un grupo de presión dentro de la organización internacional (G-4). Asimismo, la representación brasileña hizo ante la Asamblea General una propuesta para ampliar el Consejo a 25 miembros (Rodríguez Larreta, 2005: 10).

$\mathrm{Al}$ mismo tiempo, en el marco de la iniciativa IBSA, el gobierno brasileño también promueve la reforma del sistema de Naciones Unidas, teniendo en cuenta que los tres países poseen las mismas pretensiones de asegurar un lugar permanente en el Consejo de Seguridad, sin competir entre ellos por no pertenecer a la misma región. ${ }^{13}$

Este tema ha formado parte de la agenda brasileña en diversos foros multilaterales. En las sesiones de la Asamblea General, ${ }^{14}$ en septiembre de 2003, el gobierno brasileño manifestó: "es preciso que el Consejo de Seguridad esté plenamente equipado para enfrentar crisis y lidiar con las sucesivas amenazas a la paz. Por ello, en lo que se refiere a sus miembros permanentes, su composición no puede ser la misma que cuando la ONU fue creada hace más de 60 años" (Arraes, 2005: 9). Posteriormente, en junio de 2005, en su discurso ante el Foro Económico Mundial, el presidente brasileño sostuvo que: "si la ONU estuviese más democratizada y más países estuviesen presentes en el Consejo de Seguridad, ciertamente no hubiésemos tenido una guerra en Irak como tenemos, por decisión unilateral de un país" (Arraes, 2005: 10). Nuevamente en su discurso ante la Asamblea General de Naciones Unidas en septiembre de 2006, el presidente Lula Da Silva expresó: "Brasil promueve la expansión del Consejo de Seguridad con el ingreso de países en desarrollo como miembros permanentes con el objeto de lograr un organismo más democrático, legítimo y representativo (...) No es posible enfrentar nuevos problemas utilizando estructuras obsoletas". ${ }^{15}$

Otro de los medios utilizados para demostrar un mayor protagonismo internacional ha sido su participación reciente en diversas operaciones para el mantenimiento de la paz de Naciones Unidas. A partir de la década de 1990, Brasil no sólo puso al servicio de la organización internacional a sus militares, sino que también envió civiles y policías provenientes de los tres poderes, de los estados y del Distrito Federal. El costo de la participación de los observadores fue absorbido por el presupuesto de las Fuerzas Armadas

13 Sobre la base de diversas negociaciones, Brasil habría buscado el apoyo a su candidatura, en principio, de Venezuela, Perú, Bolivia y Chile (en América del Sur); Sudáfrica y Angola (en África), Alemania, Rusia, Francia, Gran Bretaña, Espańa y Portugal (en Europa) y China, Corea del Sur y Siria (en Asia) (Arraes, 2005: 9).

14 El presidente brasileńo ha participado en estas sesiones todos los ańos desde el inicio de su gestión en 2003. Cabe aclarar que en 2005 también participó de las reuniones del Consejo de Seguridad como miembro no permanente.

15 Discurso de Luis Ignacio Lula Da Silva en las sesiones de la Asamblea General de Naciones Unidas, Nueva York, 19 de septiembre de 2006. En sitio web: http://www.un.org/webcast/ga/61/pdfs/brasil-e.pdf 
Gladys Lechini y Clarisa Giaccaglia

brasileñas, situación que se vio afectada a lo largo de la década por los avatares económicos por los que atravesó el país (Cortes, 2003).

Brasil formó parte de estas operaciones en África (Angola, Uganda y Ruanda, Liberia, Mozambique y Sudáfrica); en Europa (ex Yugoslavia); en Asia (Camboya y Timor Oriental) y en América Latina (El Salvador, Guatemala y actualmente Haití) (Cortes, 2006). En el caso de Haití, es importante señalar la abstención brasileña en el Consejo de Seguridad para el envío de una misión de paz a ese país en 1994, reivindicando el derecho a la soberanía e independencia de los Estados, y el cambio de posición diez años después durante el gobierno de Lula.

Por otra parte, también Brasil sostiene su interés primordial por participar en el establecimiento de las normas económicas internacionales que apunta a desempeñar un destacado rol de líder regional. En efecto, en la Quinta Conferencia Ministerial de la OMC celebrada en Cancún en septiembre de 2003, por iniciativa del gobierno brasileño surgió el G-20 como grupo de presión que busca la eliminación o la reducción de los subsidios agrícolas por parte de las economías centrales. El gobierno brasileño viene promoviendo de forma elocuente este tipo de medidas, tal como lo expresó su ex canciller Celso Lafer en relación con un acuerdo Mercosur-Unión Europea: "se deben definir disciplinas para la eliminación de subsidios, especialmente en el área agrícola (...) No sería razonable solicitar al Mercosur que abra su mercado a productos europeos pesadamente subsidiados, que podrían dislocar la producción interna” (Lafer, 2001). Cabe aclarar que la creación del G-20 fue una oportunidad para Brasil de renovar su rol como "intermediario indispensable” entre fuertes y débiles (Soares de Lima-Hirst, Mónica, 2006: 7).

No obstante, a partir de la Sexta Conferencia Ministerial de la OMC en Hong Kong, la participación de Brasil en el G-4 o nuevo cuadrángulo, ${ }^{16}$ reflejó las divergencias existentes entre un gran país en desarrollo como el brasileño y otros estados más pequeños. En esta reunión, Brasil e India parecieron dispuestos a aceptar las condiciones exigidas por los poderes del Norte y trataron de lograr el consentimiento de las restantes naciones en desarrollo.

Desde una posición crítica a la India y Brasil, Bello sostuvo que: "resulta paradójico que el G-20, cuya formación capturó la imaginación del mundo en desarrollo durante la Ministerial de Cancún, haya acabado por ser la plataforma de lanzamiento de la integración de India y Brasil a la estructura de poder de la OMC. Pero no es un caso poco común en la historia" (Bello, 2006).

En la siguiente Conferencia Ministerial que se desarrolló en Ginebra, del 21 al 30 de julio de 2008, las negociaciones volvieron a fracasar por la falta de consenso. En esta ocasión, el cambio más sensible fue la aceptación de Brasil de la propuesta de las potencias centrales, alejándose de esta forma del frente del G-20 de los países en desarrollo, generando incertidumbre acerca de cuáles serían los posteriores pasos del gobierno brasileño.

16 El G-4 está formado por Estados Unidos, la Unión Europea, Brasil e India. 
Como se pudo observar, los diversos discursos y acciones del gobierno brasileño evidencian sus pretensiones de consolidar al país como líder en los foros diplomáticos mundiales. En consecuencia, Brasil elige aquellos espejos que incluso "agrandan" su imagen, más allá de lo que sus efectivas potencialidades le conceden, con el objeto de mantenerse como un centro de poder en el escenario internacional.

\section{b) En el ámbito regional: el espacio con los pares}

Cuando Lula inició su primer mandato, parecía dispuesto a promover el papel de Brasil como líder regional, explicando este rol por la fuerza de las cosas (territorio, población, crecimiento económico, desarrollo tecnológico). En ese sentido, el presidente dejó claras sus intenciones en un discurso al momento de asumir la presidencia: "Todos los países de América del Sur ven a Brasil como un líder natural y Brasil hace 500 años que no lo ve y no quiere serlo. Brasil tiene que asumir su grandeza" ${ }^{17}$ De esta manera, "en vez de negar la intención de ejercer cualquier forma de liderazgo en la región, el actual gobierno parecía considerarlo algo natural" (Souto Mayor citado por De Almeida, 2006).

Paralelamente, Itamaraty se empeñaba en desmentir todo propósito de hegemonía. En palabras de Luiz Filipe de Macedo Soares, encargado de las relaciones de Brasil con América del Sur:

"Brasil tiene plena conciencia de sus miserias, por eso es fundamental que tengamos una relación muy fuerte con nuestros vecinos en todos los campos. Hace 20 años que con la Argentina trabajamos en la búsqueda de una relación prioritaria, porque ninguno de los dos podrá desarrollarse solo. Brasil no busca una posición hegemónica para aprovecharse de la relación con sus vecinos". ${ }^{18}$

Las aparentes contradicciones discursivas se resolvieron cuando el presidente aceptó la estrategia de la cancillería brasileña, por la cual tanto Itamaraty como Lula niegan cualquier alusión explícita al "liderazgo brasileño" optando, según palabras del presidente, por tener una "influencia política sin liderazgo" en América Latina. ${ }^{19}$

A pesar del discurso, Brasil busca la aprobación de los estados vecinos por medio de una estrategia que relativiza los intentos de hegemonía, debido a que el reconocimiento del status de potencia media por parte de los Estados del área contigua resulta importante para el despliegue de un liderazgo regional. El gobierno brasileño elige en el ámbito

"El precio del liderazgo regional", diario La Nación, 20 de junio de 2004

8 “Reconocen que hay límites en la relación”, diario La Nación, 9 de diciembre de 2004.

19 Entrevista al presidente Lula Da Silva, diario El País, Madrid, 3 de noviembre de 2006 en Gratius, Sussane; "Lula de nuevo: ¿̇influencia regional sin liderazgo?, Fundación para las Relaciones Internacionales y el diálogo exterior (FRIDE), p. 6. En sitio web: http://www.fride.org/File/ViewLinkFile.aspx?FileId=1215 
Gladys Lechini y Clarisa Giaccaglia

regional "mirarse" en los espejos que minimizan su reflejo con el objeto de evitar todo recelo o desentendimiento con sus vecinos.

A pesar de estos cuidados al gobierno brasileńo le ha sido imposible evitar los roces a la hora de optar entre preservar el liderazgo o defender intereses nacionales sectoriales y disensos interburocráticos. Sucede que el ejercicio del liderazgo de Brasil todavía cuenta con resistencias internas y externas. Desde la perspectiva interna, hay varias cuestiones no menores que afectan la decisión, la capacidad de iniciativa o el sustento para respaldar su liderazgo. Por una parte, en ciertos sectores aún persiste la visión aislacionista que niega o cuestiona el interés y las motivaciones para que Brasil corra con los costos del liderazgo. Asimismo, son evidentes las dificultades para construir consenso interno en el marco de un mosaico complejo de variados intereses ideológicos, regionales y sectoriales. Entre los argumentos esgrimidos se apunta el del reconocimiento de los obstáculos y limitaciones de la propia realidad brasileña en todos los planos nacionales: social, económico y ético (Danese, 2001: 5).

Sin embargo, es de notar que la propia constitución federal le asigna "un destino manifiesto" al determinar que Brasil "buscará la integración económica, política, social y cultural de los pueblos de América Latina (Artículo 4, párrafo único), confiriéndole un mandato a los gobernantes para que procuren ejercer algún liderazgo regional".

En cuanto a la óptica externa, en repetidas oportunidades se le ha negado a Brasil la legitimidad o la capacidad para ejercer el liderazgo regional. Sus acciones muchas veces han sido interpretadas como un acto de poder, búsqueda de prestigio, gesto unilateral o intento de imponerse sobre los demás.

En este contexto las menciones explícitas a la cuestión del liderazgo se reducen significativamente y se encuentran inmersas en un discurso que apela con fuerza a la iniciativa conjunta. A modo de ejemplo se citan las palabras de Lula Da Silva en la Cumbre de América Latina y el Caribe sobre Integración y Desarrollo: "As incertezas que o mundo vive tornam mais urgente conjugarmos esforços e demonstrarmos liderança na busca de soluçóes inovadoras e solidárias. Os diferentes mecanismos de integraçáo em nossa região oferecem um sólido ponto de partida" (Lula Da Silva, 16/12/2008).

Esta posición podría explicarse desde dos dimensiones. En el marco doméstico, asumir un liderazgo explícito conllevaría un alto costo político. La mayor oposición proviene de los sectores industriales brasileños identificados con la política neoliberal que llevó adelante el gobierno de Fernando Cardoso, los cuales consideran que "la relación de Brasil con sus países vecinos debe limitarse al comercio (...) Las relaciones políticas con países como Argentina, Bolivia y Venezuela, por ejemplo, son vistas por la oposición como algo negativo porque puede perjudicar las relaciones de Brasil con Estados Unidos" (Gonçalves, 2007). A dichas críticas se suman ciertos medios de comunicación, como el influyente periódico O Estado de Sao Paulo o el semanario Veja, y algunos diplomáticos brasileños que escriben regularmente sobre política externa como Luiz Augusto Souto Mayor o Rubens Antonio Barbosa (De Almeida, 2006: 106-108). En términos generales, se sostiene que Brasil acepta demasiadas políticas contra sus intereses 
económicos para ganar el apoyo regional (Christensen, 2006). Incluso ciertos sectores del propio gobierno se oponen a esta estrategia. A modo de ejemplo, el entonces Ministro de Economía Antonio Palocci aseguró que no estaba dispuesto a poner en riesgo la economía local generando déficits comerciales sólo para conquistar a los vecinos. ${ }^{20}$

Desde una perspectiva externa, los socios regionales no parecen estar muy de acuerdo con la aceptación de un líder que no esté dispuesto a correr con los costos de tal actitud. En ese contexto, Brasil ha tenido que sortear varias situaciones complejas. Es ejemplificador al respecto el caso de Paraguay y Uruguay, los dos socios menores del Mercosur, cuando critican la falta de mecanismos que tengan en cuenta las asimetrías entre sus débiles economías y la brasileña.

A pesar de que Lula se ha ocupado de remarcar en las reuniones bilaterales que considera a la Argentina como un "par" o "socio", en Buenos Aires quedan dudas sobre el rol que le tiene reservado Brasil. En un discurso en esa capital en agosto de 2008, el presidente brasileño expresó: "Argentina e o Brasil podem liderar a resposta do Mercosul e da América do Sul a desafios actuales. Nossa aliança estratégica é a espinha dorsal desse projeto" (Lula Da Silva, 04/08/2008).

También existen contradicciones en Argentina sobre cómo se percibe a Brasil y qué se espera de esta relación. Algunos sectores del gobierno y la cancillería argentina prefieren la hegemonía norteamericana a la regional brasileña, otros aceptan la posición de hegemonía cooperativa -ya abandonada la idea de la superioridad Argentina de principios del siglo XX- aunque en esta relación queda por definir si Argentina será México o Canadá en su sociedad con Brasil. También está claro que Argentina necesita de Brasil para desarrollar una política regional y juntar fuerzas en un escenario internacional cada vez más complicado, pero no puede ni debe dejar la negociación de todas las cuestiones económicas y políticas internacionales en manos de su socio mayor, pues existen cuestiones pendientes con intereses en conflicto.

Durante los últimos años los gobiernos argentinos no han podido desarrollar estrategias coherentes y activas de inserción internacional, limitándose en la mayoría de los casos a políticas reactivas. A esta situación se han sumado las dificultades existentes entre ambos presidentes para coincidir en la misma sintonía, a pesar de las supuestas afinidades ideológicas.

Desde el punto de vista de Argentina, se ha observado cierta incomodidad por algunas actitudes y decisiones brasileñas. Roberto Miranda (2006: 4) señala tres ocasiones en la cuales se vio reflejada esta tensión. La primera situación se manifestó durante la Cumbre Extraordinaria de las Américas, celebrada en Monterrey en enero de 2004. La molestia argentina estuvo centrada en el hecho de que Brasil, en su condición de líder, no promovió una ofensiva reivindicatoria del Mercosur, tal como esperaba el gobierno argentino, sino que adoptó un bajo perfil. Esta actitud contrastó significativamente con

20 Diario La Nación, 20 de junio de 2004. 


\section{Gladys Lechini y Clarisa Giaccaglia}

el protagonismo que Brasil había tenido durante la Ronda Doha de Cancún y en las negociaciones por el Área de Libre Comercio de las Américas (ALCA) tan sólo unos meses antes, en septiembre y noviembre de 2003, respectivamente.

El segundo suceso fue en el momento de la creación de la Comunidad Sudamericana de Naciones, ${ }^{21}$ en diciembre de 2004. Dicha iniciativa estuvo caracterizada por una marcada impronta brasileńa sin mediar ningún encuentro previo con Argentina para coordinar posiciones. En relación a este tema resulta importante señalar que no sólo la diplomacia argentina sino también la mexicana ven esta propuesta como un intento de formación de un bloque centrado en Brasil y, en consecuencia, demuestran una gran cautela.

Sin embargo, y a pesar de las posibles resistencias, el Estado brasileño se mantiene como el principal articulador del proyecto integracionista de Sudamérica, fortaleciendo su presencia como líder regional. ${ }^{22}$

La última ocasión señalada por Miranda, en la que la actitud brasileńa produjo malestar en Argentina, refiere a la crisis institucional ecuatoriana de abril de 2005..$^{23}$ En dicha oportunidad, Brasil buscó imponer la actuación de la Comunidad Sudamericana de Naciones para enfrentar la crisis -ámbito en el que, como recién se mencionó, el gobierno brasileño tiene un claro protagonismo- mientras que Argentina planteó adoptar una posición conjunta y común entre esta Comunidad, la Organización de Estados Americanos y el Grupo de Río (Miranda, 2006: 5).

Un nuevo capítulo se sumó al devenir de Unasur, a principios de 2010, con el nombramiento de Néstor Kirchner como Secretario General del organismo regional. Desde la presidencia brasileńa, Lula Da Silva declaró que estaba "cien por cien" de acuerdo con la designación del ex presidente argentino porque "tiene experiencia, conoce el continente y las diferencias políticas e ideológicas que tenemos"(diario El Mundo, 04/05/2010). El apoyo a esta candidatura estaría explicado por la necesidad de Brasil de presentar ante el mundo la imagen de una Unasur consolidada con respaldo de sus pares regionales. No obstante, desde muchos sectores políticos y académicos, se relativiza esta presencia argentina advirtiendo que Brasil constituye el verdadero hacedor y líder del grupo.

21 La Comunidad Sudamericana de Naciones (hoy Unasur) pretende, sobre la base de un acuerdo Mercosur-CAN, lograr la integración física e institucional de la región en un plazo de 15 ańos. Las conveniencias de este proyecto para Brasil radican en mejores accesos al Pacífico, en especial vía Bolivia-Perú; y al Caribe, vía Colombia-Venezuela. Además, la Comunidad le permitiría un aprovechamiento del potencial hidroeléctrico de Venezuela y Guyana, petrolero de Venezuela y gasífero de Bolivia.

22 Al representar Brasil cerca de dos tercios del piB total del Mercosur, "su evolución económica, sus políticas internas y su posición negociadora dentro del bloque, condicionan prácticamente la evolución global del proceso de integración, su metodología y su agenda de negociaciones". Paralelamente, la actitud brasileña en relación con las negociaciones externas del bloque, por ser el socio mayor, define lo que se identifica como "posición Mercosur" (Da Mota Veiga, 2001).

23 En abril de 2005, el presidente ecuatoriano Lucio Gutiérrez se convirtió en una figura controvertida cuando decidió reemplazar con sus partidarios a muchos de los jueces de la Corte Suprema, decisión que provocó una inmensa protesta pública y manifestaciones en todo Ecuador. Finalmente, Gutiérrez fue removido asumiendo el cargo su vicepresidente Alfredo Palacio. 
Otra de las cuestiones que genera ruido entre ambos países es la pretensión de Brasil de obtener un asiento permanente en el Consejo de Seguridad de Naciones Unidas si se reformara la Carta. ${ }^{24} \mathrm{Si}$ en estos últimos años se han logrado fórmulas intermedias que incluyen al socio Mercosuriano en la participación de ambas delegaciones cuando ejercen sus funciones como miembro no permanente en ese Consejo el tema sigue siendo problemático.

La ubicación de Argentina y Brasil en diferentes posiciones en las negociaciones desarrolladas en la ya mencionada Conferencia Ministerial de la OMC en Ginebra, en 2008, provocó malestar en la relación bilateral, fundamentalmente del lado argentino. Esto se debió a la aceptación por parte del gobierno brasileño de la propuesta realizada por las potencias centrales alejándose de esta forma de los países en desarrollo (del G-20, del G-33 y del NAMA-11).

Frente a ello, algunos sectores argentinos calificaron el accionar de Brasil como "traición” (Tussie, 2008). Asimismo, el Secretario de Comercio Internacional de la cancillería argentina, Alfredo Chiaradía, consideró que la posición brasileña "no sería gratuita” y destacó los inconvenientes que podría ocasionar esta situación tanto dentro del Mercosur, debido a que se trata de un bloque regional que se rige por un arancel común que debe ser respetado, como en el G-20. "Por eso cada uno tendrá que asumir sus responsabilidades". ${ }^{25}$

El presidente brasileño, por su parte, aseguró que no existía ninguna hipótesis de que Brasil "se juegue solo" al tiempo que Itamaraty concentraba los esfuerzos en recomponer la relación y el canciller Celso Amorim declaraba que, pese a las diferencias entre la Argentina y Brasil en Doha, "el entendimiento político bilateral es excelente. Vamos a seguir hablando y estoy seguro de que vamos a encontrar una posición conjunta muy bien definida". ${ }^{26}$ De esta forma se recurrió nuevamente a los elementos discursivos aglutinadores a fin de restaurar los vínculos bilaterales.

Argentina y Venezuela son para Brasil dos socios claves en lo que considera su ámbito regional, América del Sur, con dos proyectos -Unasur y Mercosur- donde Brasil puede ejercer su "influencia sin liderazgo", en palabras de Lula o "liderazgo positivo", según Amorim. ${ }^{27}$

Con respecto a Venezuela, Lula sostiene una relación crítica y compleja con Hugo Chávez y sus pretensiones de liderazgo regional. En este sentido Brasil debe mantener un delicado equilibrio con un país cuyo presidente plantea un proyecto contrahegemónico cargado de simbolismos y expresiones antinorteamericanas y nacionalistas, sumado a las acusaciones veladas que recibe de ser el encargado de Washington para “contener” a Chávez.

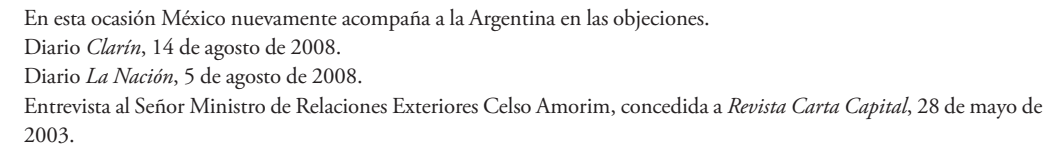




\section{Gladys Lechini y Clarisa Giaccaglia}

Otro tema ríspido que debió afrontar Lula en la región fue con su vecino Bolivia. ${ }^{28}$ En el proceso de renegociación de las nacionalizaciones de hidrocarburos una de las empresas más afectadas fue Petrobras, que esperaba contar con el apoyo de su gobierno. En medio de la campańa presidencial para su segundo mandato, Lula Da Silva estaba presionado tanto por sus opositores -que lo acusaban de no defender los intereses nacionales brasileños- como por la relación con Evo Morales y los movimientos de la izquierda latinoamericana -que pretendían el apoyo del presidente al proceso transformador boliviano. El caso puso a prueba las posibilidades y limitaciones de Brasil para actuar como líder regional y compatibilizar sus intereses con las demandas de la región. No obstante, la situación se mantuvo bajo control y los intereses brasileños y bolivianos fueron compatibilizados en el marco de la estrategia brasileña de manejar las turbulencias que puedan amenazar la estabilidad regional.

Por otra parte, una situación que muestra las aristas de un complejo juego interno-internacional es la participación de Brasil en la intervención de Haití. Recordemos que en el 2004, el gobierno brasileño decidió asumir el mando militar de la Misión de Estabilización de las Naciones Unidas para Haití (MINUSTAH) enviando un contingente de 1.200 efectivos. Se trata de la primera intervención militar de Brasil en un país de El Caribe, lo cual recibió fuertes críticas de diversos sectores de la sociedad que catalogaron el suceso como un abandono del histórico principio de no intervención en los asuntos de terceros Estados. Frente a esto, la cancillería brasileña buscó defenderse asegurando que no se debía confundir la "no intervención" con la falta de interés o la indiferencia a los problemas regionales. El contingente brasileño establecido en Haití adoptó una posición neutral manteniendo las bandas armadas separadas para evitar la muerte de soldados brasileños (Gauthier-De Sousa, 2006: 4).

Finalmente, cabe mencionar la controversia que mantienen los gobiernos de Argentina y Uruguay por la instalación de la papelera Botnia. En las últimas negociaciones, en junio de 2010, dichos mandatarios acordaron un monitoreo conjunto del río Uruguay en el cual también se incorporaría a Brasil. Resulta significativo destacar que frente a este proceso de negociación caracterizado por altos niveles de tensión que continúan hasta el día de hoy, el gobierno brasileño ha mantenido una prudente distancia. En este sentido, deben entonces entenderse las recientes declaraciones oficiales realizadas por un portavoz de Itamaraty, quien sostuvo: "por el momento nadie de Argentina o de Uruguay hizo un pedido oficial para el monitoreo. Brasil se pronunciará en caso de que

\footnotetext{
28 La ascención de Evo Morales implicó la puesta en práctica de una política nacionalizadora de los recursos naturales estratégicos, considerándose al gas como un valor para ser resguardado para garantizar la emancipación de las poblaciones pobres e históricamente marginadas. De este modo, el $1^{\circ}$ de mayo de 2006, mediante el Decreto Supremo $\mathrm{N}^{\circ} 28701$, que establece que el Estado recupera la propiedad, la posesión y el control total y absoluto de los hidrocarburos, el gobierno del Movimiento al Socialismo (MAS), nacionalizó estos recursos, le otorgó a la empresa estatal Yacimientos Petrolíferos Fiscales de Bolivia (YPFB) la dirección y control de todas las operaciones petroleras y comenzó a renegociar todos los contratos otorgados a las empresas del sector de acuerdo con la nueva legislación.
} 
se lo soliciten" (ANSA, 24/06/2010). De esta manera, el gobierno brasileño buscó nuevamente moderar su participación en los entredichos sudamericanos.

\section{LIDERAZGO SÍ, LIDERAZGO NO... LAS PARADOJAS DE BRASIL}

Desde el punto de vista discursivo, Brasil lleva adelante una doble estrategia, actuando de forma ambivalente, esto es, diferenciando su comportamiento según se trate del ámbito internacional o regional. Las paradojas en el comportamiento de Brasil se hacen patentes en variados discursos oficiales, en los cuales las locuciones empleadas van modificándose en función de los oyentes.

En las esferas internacionales, el gobierno brasileńo generalmente asume y admite su liderazgo a la hora de negociar cuestiones de diversa índole que involucran de forma directa sus intereses nacionales. El auto-reconocimiento del liderazgo brasileńo se observa con más fuerza cuando el ejecutivo se reúne con representantes de otros grandes poderes mundiales, frente a los cuales parecería que quiere dejar clara su importancia decisiva en este lado del mundo. De esta manera promueve un rol protagónico para su país en todos los escenarios en donde las grandes potencias poseen una posición consolidada como el Consejo de Seguridad de Naciones Unidas, las rondas de negociación de la Organización Mundial del Comercio o las reuniones del G-7. Brasil busca lograr mayores márgenes de maniobra en el sistema internacional y su reconocimiento como uno de los centros de poder mundial.

En el ámbito regional, en cambio, la administración brasileńa suele eludir cualquier alusión explícita a su liderazgo, enfatizando expresiones que denotan un accionar conjunto que ubica a Brasil como un par o un socio más. Esta última actitud se agudiza en los encuentros bilaterales con Argentina, con la cual, generalmente desmiente todo propósito de liderazgo.

Esta posición con sus pares puede explicarse por tres cuestiones principales. En primer lugar, la resistencia de la sociedad brasileña a que el país asuma mayores responsabilidades mundiales con sus consiguientes mayores costos. En segundo lugar, la oposición de varios países latinoamericanos, entre ellos Argentina y México. Finalmente, las presiones ejercidas por Estados Unidos, que si bien reconoce a Brasil como un interlocutor privilegiado en el área, no permitirá un accionar que contradiga sus propios intereses.

En suma, la actual política exterior brasileña no elige un único camino para alcanzar sus objetivos y, por ende, no se ubica totalmente del lado de los países desarrollados pero tampoco defiende un discurso de confrontación con las grandes potencias. Brasil circula por el laberinto de espejos ubicándose frente al que exalta o empequeńece su imagen según lo impongan las circunstancias. Dicha estrategia parece haber dado buenos resultados para los intereses brasileños, permitiendo el mantenimiento de un delicado equilibrio de buenas relaciones tanto con los vecinos como con las grandes potencias. 


\section{Gladys Lechini y Clarisa Giaccaglia}

Sin embargo, en ciertos momentos el discurso ambivalente de Brasil no puede mantenerse en carriles separados, es decir, un discurso a nivel global y otro a nivel regional, ya que determinadas cuestiones se entrecruzan generando complicaciones para el gobierno brasileño, tal como se observó en las posiciones tomadas en Ginebra en la última reunión de la OMC.

En aquellos casos en los que las argumentaciones componedoras no terminan de convencer, la administración brasileña recurre a un férreo pragmatismo, dejando en claro la prioridad de la defensa de sus intereses nacionales. Este pragmatismo puede encontrarse en declaraciones tanto del presidente como de su canciller. En palabras de Celso Amorim, en relación a los vínculos con Argentina, expresó: "Que seamos vecinos, socios, amigos y hermanos no impide que cada país negocie con su cabeza y según sus necesidades". ${ }^{29}$

En cuanto al presidente Lula Da Silva, señaló al respecto: "por más que usted trabaje en un proceso de integración, en algunos momentos usted tiene que tomar en cuenta la situación de su Estado nacional". ${ }^{30}$ "Todos los Estados pueden trabajar en forma conjunta. Pero ninguno abandona su soberanía. Argentina tiene sus intereses y Brasil los suyos". 31

Por último en una entrevista reciente el presidente brasileño afirmó: "Nunca tuve un trauma por haber cambiado de postura porque veo la política con un gran pragmatismo. En política se hace lo que se puede hacer. En el discurso uno puede decir lo que quiere, pero en el momento de ejecutar, el límite es lo posible". ${ }^{32}$

Posiblemente sea el gran pragmatismo desarrollado por los ejecutores de la política externa brasileña lo que le ha permitido a Brasil sostener a lo largo del tiempo la línea de defensa de los intereses nacionales, cada vez más complejos, en un camino, muchas veces zigzagueante.

Los liderazgos se construyen y tienen costos, así como beneficios. Puede que "la hora” de Brasil esté cerca. Pero por el momento, deberá aguardar algún tiempo para lograr conciliar sus expectativas con sus capacidades, sobre la base del armado de una compleja ingeniería de apoyos domésticos y regionales, que le permitan consolidarse como potencia media pudiendo finalmente mostrar su "verdadero reflejo".

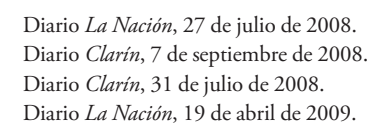


El ascenso de Brasil en tiempos de Lula zlíder regional o jugador global?

\section{BIBLIOGRAFÍA}

Arraes, Virgilio, "O goberno Lula e o Conselho de Segurança”, en Meridiano 47, revista del Instituto Brasileño de Relaciones Internacionales, Brasilia, núm 64, noviembre de 2005. Disponible en: http://boletim.meridiano47.googlepages.com/meridiano_64.pdf Consultado en marzo de 2010.

Barbé, Esther, Relaciones Internacionales, Madrid, Tecnos, 1995.

Behringer, Ronald, "Middle Power Leadership on Human Security", paper presentado en el Annual Meeting of the Canadian Political Science Association, Halifax, Nova Scotia, 30 de mayo de 2003. Disponible en: http://www.cpsa-acsp.ca/paper-2003/ behringer.pdf Consultado en marzo de 2010.

Bello, Walden, "El verdadero significado de Hong Kong”, 2006 Disponible en: http:// www.bolpress.com/art.php Consulta 12/2007 Consultado en noviembre de 2009.

"Brasil no fue consultado por monitoreo de pastera Botnia", ANSA, 24/06/2010. Disponible en: http://abc.com.py/abc/nota/139300-Brasil-no-fue-consultado-pormonitoreo-de-pastera-Botnia/ Consultado en junio de 2010.

Christensen, Steen Fryba, "La política energética de Bolivia y las relaciones entre Bolivia y Brasil”, Sociedad y Discurso, revista electrónica de Español y Estudios Internacionales del Departamento de Lenguas, Cultura y Estética, Universidad de Aalborg, Dinamarca, no 10, 2006. Disponible en: http://www.discurso.aau. $\mathrm{dk} / \mathrm{dec} \% 2006 \% 20$ no10/Sociedad\%20y\%20discurso\%20Nr.10-final/Steen.pdf Consultado en abril de 2010.

Carpena, Ricardo, Entrevista con Luis Inacio "Lula" Da Silva: "No puedo imaginar a Brasil y la Argentina separados”, en diario La Nación, Buenos Aires, 19/04/2009.

Cortes, María Julieta, "El multilateralismo en la política exterior de Brasil en los 90. El Consejo de Seguridad y su participación en OMP”, presentado en VII Jornadas de la Asociación Argentina de las Relaciones Internacionales: "América Latina frente al poder global. Crisis y desafíos”. Facultad de Ciencias Económicas de la Universidad de Buenos Aires, Buenos Aires, 22 al 24 de octubre de 2003.

Cortes, María Julieta, "La política exterior brasileña en los 90. Continuidades y ajustes”, Tesis de maestría, Facultad Latinoamericana de Ciencias Sociales, Rosario, febrero de 2006.

Da Mota Veiga, Pedro, "Brasil, el Mercosur y el ALCA", en revista Foreign Affairs en español, México, primavera 2001. Disponible en: http://www.foreignaffairs-esp. org/20010201 faenespessay4836/pedro-da-motta-veiga/brasil-el-mercosur-y-el-alca. html Consultado en mayo de 2010.

De Almeida, Paulo Roberto, "Uma nova 'arquitetura' diplomática? Interpretaçoes divergentes sobre a política externa do gobernó Lula (2003-2006)”, en Revista Brasileira de Política Internacional (RBPI), año 49, núm. 1, 2006.

"Defiende Brasil la negociación de Doha", diario La Nación, sección economía, Buenos Aires, 19/08/2008. 
Gladys Lechini y Clarisa Giaccaglia

Discurso del presidente Lula Da Silva, en la apertura del Encuentro empresarial BrasilArgentina, 04/08/2008, Disponible en: http://www.mre.gov.br/espanhol/politica externa/discursos/discurso Consultado en abril de 2010.

Discurso del presidente Lula Da Silva, en la apertura de la Cumbre América LatinaCaribe sobre Integración y Desarrollo, 16/12/2008. Disponible en: http://www. mre.gov.br/espanhol/politica_externa/discursos/discurso_Consultado en mayo de 2010.

Discurso del ministro de Relaciones Exteriores, Celso Amorim, en Seminario organizado por los periódicos Valor Econômico y The Wall Street Journal, New York, 16/03/2009. Disponible en: http://www.mre.gov.br/espanhol/politica_externa/discursos/discurso_detalhe3.asp?ID Consultado en mayo de 2010

Drezner, Daniel, "El nuevo orden mundial nuevo", en revista Foreign Affairs en Español, Julio-Septiembre de 2007.

Fonseca Jr., Gelson, “A Legitimidade e Outras Questôes Internacionai”, Paz e Terra, San Pablo, 1998.

"Fracasó la liberalización del comercio mundial", diario La Nación, sección economía, Buenos Aires, 30/07/2008.

Gauthier, Amélie y Sarah John de Sousa, "Brasil en Haití: el debate respecto a la misión de paz", Fundación para las Relaciones Internacionales y el diálogo exterior (FRIDE), noviembre de 2006. Disponible en: http://www.fride.org/File/ViewLinkFile. aspx?FileId=1180 Consultado en noviembre de 2009.

Giaccaglia, Clarisa, "Pequeños gigantes del sistema internacional: un estudio sobre la naturaleza y las funciones de las potencias medias", Tesis de grado de la Licenciatura en Relaciones Internacionales de la Facultad de Ciencia Política y Relaciones Internacionales de la Universidad Nacional de Rosario, mimeo, diciembre de 2006.

Gonçalves, Williams, "Hegemonismo ou Liderança? A política externa do Brasil para a América do Sul", entrevista personal de las autoras, Río de Janeiro, 2 de abril de 2007.

Holbraad, Carsten, Las potencias medias en la política internacional, México, Fondo de Cultura Económica, 1989.

Hurrell, Andrew, "Some Reflections on the Role of Intermediate Powers in International Institutions", Latin American Program, Woodrow Wilson International Center for Scholars, Toronto, marzo de 2000. Disponible en: www.wilsoncenter.org/index.cfm Consultado en noviembre de 2009.

"India se suma al reclamo argentino y brasileño", diario La Nación, sección economía, Buenos Aires, 24/07/2008.

"Irán, tema del viaje de Lula por Rusia", BBC Mundo, Londres, 13/05/2010. Disponible en:http://www.bbc.co.uk/mundo/america_latina/2010/05/100513_brasil_rusa_ lula_iran_az.shtml Consultado en mayo de 2010.

Keohane y Nye, Poder e interdependencia. La politica mundial en transición, Buenos Aires, GEL, 1988. 
Lafer, Celso, "El MERCOSUR entre el ALCA y la Unión Europea y las perspectivas para la relación Brasil-Alemania”, ponencia presentada por el Ministro de Relaciones Exteriores de Brasil, en la Cámara de Comercio e Industria Brasil-Alemania, Sao Paulo, 8 de junio de 2001. Disponible en: http://www.mre.gov.br/espanhol/merco$\mathrm{sul} / \mathrm{mercosur} / \mathrm{uniao}$.asp Consultado en abril de 2010.

"Néstor Kirchner asume el cargo de secretario general de Unasur", diario El Mundo, 04/05/2010. Disponible en: http://www.elmundo.es/america/2010/05/04/argentina/1272987864.html Consultado en junio de 2010.

"No puedo imaginar a Brasil y la Argentina separados", entrevista realizada a Luiz Inácio Lula da Silva por Ricardo Carpena, en Diario La Nación, Buenos Aires, 19/04/2009.

Nolte, Detlef, "Potencias regionales en la política internacional: conceptos y enfoques de análisis", German Institute of Global and Area Studies (GIGA), núm. 30, 2006. Disponible en: http://www.giga-hamburg.de/content/publikationen/pdf/wp30_ nolte.pdf

Nye, Joseph, La naturaleza cambiante del poder norteamericano, Buenos Aires, Grupo Editor Latinoamericano, 1991.

Moniz Bandeira, Luis Alberto, Argentina, Brasily Estados Unidos: de la Triple Alianza al MERCOSUR, Buenos Aires, Grupo Editorial Norma, 2004.

Perez Llana, Carlos, “¿Potencias intermedias o países mayores? La política exterior de la Argentina, el Brasil y México”, en Relaciones Internacionales de la América Latina, Selección de Luciano Tomassini, México, Fondo de Cultura Económica, 1981.

Pinheiro, Letícia, Política Externa Brasileira, 1889-2002, Río de Janeiro, Jorge Zahar, 2004.

Rodríguez Larreta, Aureliano, "Brasil, nueva superpotencia”, en Politica Exterior, núm 107, septiembre-octubre de 2005.

Sahni, Varun, "Drag anchor or launching pad: regional dynamics of emerging powers", presentado en la Conferencia "Poderes emergentes y seguridad regional: el caso IBSA", Universidad de San Andrés, Buenos Aires, 30 de mayo de 2006.

Soares De Lima, Maria Regina y Mónica Hirst, "Brazil as an Intermediate State and Regional Power: Action, Choice and Responsibilities", en International Affairs, 2006. Disponible en: http://www.blackwell-synergy.com/doi/abs/10.1111/j.14682346.2006.00513.x Consultado en noviembre de 2010.

“Tensión con Brasil por el comercio global”, diario La Nación, sección economía, Buenos Aires, 27/07/2008.

Tussie, Diana, "La traición de Brasil”, en diario Crítica de la Argentina, 2008. Disponible en: http://criticadigital.com/index.php?secc=nota\&nid=8485 Consultado en mayo de 2010.

Vigevani y Ramanzini Jr., "Brasil en el centro de la integración", en revista Nueva Sociedad, núm. 219, enero-febrero de 2009. 
